\title{
Viability of the seed of senecio inaequidens D C buried in field environmental conditions
}

\begin{abstract}
In order to know the period of feasibility of the seneçon du cap seeds, exposed to environmental climatic conditions, the realization of this research was proposed, in which the effect of exposing the seeds to three different burial conditions (superficial, 2 and $10 \mathrm{~cm}$.) having as a witness seeds that are kept at a constant temperature of $20^{\circ} \mathrm{C}$., to know what happens with the seeds when they are exposed to climatic variations.

In the present work, it has been proposed to evaluate the feasibility of the seeds, for a period of three years, during which samples of the seeds that have been buried in the soil at the three depths mentioned above will be sampled, the samples will be taken from the following way: during the first year, samplings will be made every fifteen days, in the second year, the samplings will be monthly and in the third year, the samplings will be bimonthly.
\end{abstract}

The results of the first 17 samplings that have been made, where the first results can be observed, on the behaviour of the viability of the seeds of this plant, it has been observed that there are statistical differences between the different levels of burial of the seeds, being greater the viability of the seeds of the control treatment, followed by the seeds that are buried to $10 \mathrm{~cm}$ of depth, then those that are $2 \mathrm{~cm}$ deep and finally those that are exposed on the surface of the soil and all statistically different each.

Finally it is observed, until sampling number $16(05 / 29 / 2001)$, that in a general way the seeds of the superficial treatment, have practically lost the viability from the sampling number six, since they present less than $10 \%$ of viability the seeds. On the contrary, the seeds of the burial treatments at 2 and $10 \mathrm{~cm}$ depth maintain a variable viability, which may be due to the variability of climatic conditions, however, much higher than those that are exposed on the surface. Also, it is observed that the seeds that are buried at $10 \mathrm{~cm}$, Retain greater viability than the seeds buried at $2 \mathrm{~cm}$ depth.

As for the seeds that do not germinate during the period of permanence in the germination chamber, they were subjected to the tetrazolium test, observing that for any of the treatments (superficial, 2 and $10 \mathrm{~cm}$ ) in which the seeds are exposed to the climatic conditions, less than $3 \%$ of said seeds remain dormant, the rest of the seeds are dead or damaged, while the seeds of the control treatment, the dormancy is higher than $15 \%$, on average.

Keywords: Senecio inaequidens, buried seeds, dormancy
Volume 3 Issue 3 - 2019

\author{
Medina MJA, J Maillet, Ruiz NRE, Coutiño \\ RRR, Araujo GJG
}

Facultad de Ciencias Agronómicas, Universidad Autónoma de

Chiapas, México

\begin{abstract}
Correspondence: José Alfredo Medina Universidad Autónoma de Chiapas, Facultad de Ciencias Agronómicas. Carretera Ocozocoautla-Villaflores, km 80.Villaflores, Chiapas, México, CP 30460,Email jmedina_2157@hotmail.com
\end{abstract}

Received: April 30, 2018 | Published: May 15, 2019

\section{Introduction}

Senecio inaequidens, (seneçon du cap) is a plant native to South Africa, ${ }^{1}$ which was observed in France by the year 1936, later identified in the vicinity of the tanneries of Mazamet, ${ }^{2}$ Being the fleeces of wool (toisons lainières) where the seeds of this plant were transported, and it is from that since 1940, this plant began to spread throughout France, always in the vicinity of the wool industry. Likewise, this plant is currently located in other European countries such as Switzerland, Spain, Italy, Germany, Denmark, Holland. ${ }^{3}$ Currently it is a weed that is in full expansion in Europe, and that can cover more than $90 \%$ of the infested surfaces. It is also a plant that predominates in prairie areas, and in non-cultivated areas. This is because there are many reports, ${ }^{4-10}$ on the production of alkaloids, by species of the genus Senecio, which cause harmful effects to the animals that consume them, ${ }^{11,12}$ and this could be one of the main causes why plant has had a strong expansion, in prairie areas, ${ }^{13}$ and as a consequence lacks the competition of other plants, because it is not consumed by animals, coupled with its high production of seeds, ${ }^{14}$ as well as for the ease of dispersion (hydrocaric and anemocic), ${ }^{2}$ by animals and man. It is also supposed to have allelopathic effects ${ }^{15}$ and for that reason it is easier to develop and cover these areas of new infestation.

However, for this strong dispersion and invasion to new areas of land to occur, it may be due to the ability of the seeds of this plant to survive climatic adversities, predation of natural enemies, and some type of dormacy. ${ }^{16}$ On the other hand, it is important to mention that climatic factors have a determining influence on the behaviour and survival of seeds, when they are exposed to environmental conditions. In this regard, there are several studies on the behaviour of seeds of different plant species, when subjected to different climatic conditions.

Temperature, seems to be one of the most important factors that decisively affect the behaviour of the seeds, with regard to dormancy, as mentioned, ${ }^{17,18}$ in Sorghum halepense, ${ }^{19}$ in Capsella bursa-pastoris, in Viola arvensis, ${ }^{20,21}$ in Malva pusilla and Erodium cicutarium, ${ }^{22}$ in Artemisia frigida, ${ }^{23}$ in Setaria glauca ${ }^{24}$ on Stellaria media. In this regard, it is mentioned that alternating changes of temperatures in day/ night relation, and depending on the species, can favor the germination or not of the seeds, united of course to the other environmental factors, such as humidity ${ }^{20}$ and light ${ }^{25}$ or soil water content. ${ }^{26}$ 
On the other hand, there are other factors that influence the behaviour of the seeds, when they are exposed in the soil. Several studies have been carried out to know what are the effects they cause on seeds, factors such as the time of permanence of the seeds buried in the soil, where it has been observed in a general way that the more superficial is the exposure of the seeds, more quickly they lose viability and on the contrary, to a greater depth of burial, they retain higher percentages of viability. ${ }^{27-29}$ Likewise, interrelation with the type of soil has been observed, which influences the viability of the seeds ${ }^{30}$ humidity and temperature, ${ }^{31}$ but as the residence time is prolonged of the seeds in the soil, these lose viability. ${ }^{22,32,33}$

Finally, in the seeds buried, germination almost totally declines, but not the viability, especially as the seeds are buried deeper, a situation that may be due to the decrease of oxygen to a greater depth of burial and a lower presence of enemies natural by the conditions of anaerobiosis. ${ }^{34,23}$

In some species of the Asteraceae family, it has been observed that they are photoblastic and require alternating temperatures to germinate ${ }^{35,36}$ and, in the case of Senecio vulgaris, it has been observed that decreasing the temperature to less than $15^{\circ} \mathrm{C}$ decreases the germination, when it is stored, but this situation presents itself in a different way depending on the origin of the population, from where the seeds were obtained. ${ }^{37}$

In order to know what happens with the viability of the seeds of Senecio inaequidens, when these remain in the ground exposed to the environmental conditions of the field, the realization of this research work was proposed exposing to three depths of burial (superficial, 2 and $10 \mathrm{~cm}$ ) during different periods of time, being the maximum of three years to know the behaviour of the seed bank, considering the following objectives:

To evaluate the viability period of Senecio inaequidens seeds, under environmental conditions and buried in the soil, for a maximum period of three years. Determine if the seeds that did not germinate after being unearthed, are dormant or are dead.

\section{Materials and methods}

Seeds of Seneçon du cap were collected on September 14, 2000, in the town of the Bagnas Natural Reserve, located in the Languedoc Roussillon region France, located at 50 m.s.n.m. Afterwards, 50 seeds of the seneçon du cap were placed in small bags of fine plastic mesh, which allows them to be exposed, but it does not allow them to come out and with this, their recovery from the soil, when the samplings are made. On October 17, 2000, the seeds were placed in the field, according to the different treatments proposed; three depths (superficial, 2 and $10 \mathrm{~cm}$ ) and a control treatment, which is maintained under temperature conditions of $20^{\circ} \mathrm{C}$, with three repetitions.

Once the treatments were established in the field, the germination of the seeds and its effects as a consequence of the burial began to be evaluated, and on October 31 when the samplings of the buried seeds began. The duration of the trial will be three years, considering as follows: during the first year, samples will be taken every 15 days; during the period of the second year, the samplings will be carried out monthly; and for the third year the samples will be every two months.

The evaluation of the viability of the seed du Senecon du cap, will be as follows: at the time of sampling, the emerged seedlings will be counted and the seeds that did not germinate will be placed in the germination chamber for a period of 10 days. days, where counts are made every 2 days of the seeds that germinate.

Once the seeds are unearthed, they are placed in circular Petri dishes of $10 \mathrm{~cm}$ in diameterx $1.1 \mathrm{~cm}$ in height, and they are placed on white filter paper of the MN40 m type of $9 \mathrm{~cm} \varnothing$, which is placed on glass balls, To favour the imbibitions of the water in a homogeneous way, finally $5 \mathrm{ml}$ of distilled water are added to the Petri dishes containing the seeds.

The lighting conditions and temperatures in the germination chamber are as follows: from 11:30 pm to $2: 00 \mathrm{pm}$; that is, a total of 14:30 hours of light, with temperatures of $24^{\circ} \mathrm{C}$ during the illuminated phase and $20^{\circ} \mathrm{C}$ in the dark phase. Osram L fluorescent tube lamps are used, 36 watts of power, $1.20 \mathrm{~m}$ long, with a total of 12 tubes per square meter $\left(\mathrm{m}^{2}\right)$, and the height of the lamps to the Petri dishes was 1 meter.

Finally, those seeds that did not germinate, are tested for tetrazolium, to know if they are viable or are dead, this test consists of transferring the seeds that did not germinate in the chamber, to the treatment with the tetrazolium solution at $1 \%$ during a period of 24 hours at $20^{\circ} \mathrm{C}$ temperature, in dark conditions..$^{38}$

The evaluation of the tetrazolium test is carried out observing the red coloration of the embryo of the seneçon du cap seeds if they are alive, or if they are dead, they no longer colour the embryo, as mentioned. ${ }^{39-41}$

\section{Experimental design and statistical analysis}

The trial was implemented in a randomized complete block design, with three repetitions, in a factorial arrangement of $4 \times 42$; being 4 , the levels of burial depth of the seeds (superficial, 2 and $10 \mathrm{~cm}$ and the control) and 42; the sampling period, during the three years of the trial, with three repetitions.

The statistical analyzes will be of analysis of variance, to define if there are differences in the viability of the seeds in the different depths of burial and through time.

\section{Results and discussion}

Below are the results of the germination behaviour and viability of the seeds during the first eight months that they have been buried in the field.

First, the variation of climatic conditions during this period is shown. Environmental conditions: During the period that the research has been developed, it has been observed that the variation of the temperature, between the surface of the soil and the $10 \mathrm{~cm}$ under the surface, there have been average differences of $7.6^{\circ} \mathrm{C}$, being always colder the temperature on the surface of the ground, that almost in its totality was smaller than $8^{\circ} \mathrm{C}$, whereas the temperatures under the surface of the ground, always were superiors to $8^{\circ} \mathrm{C}$.

It can also be observed that the insolation has been very small, since the period in which the trial started (17/10/2001), less than 2 hours a day on average, and until the end of January, which from the first days of the month of February has passed to more than 6 hours of light per day, which has increased considerably the luminosity.

Another factor that has also presented strong variations, especially that there have been too many rains during the initial stage of the investigation, can be seen that practically since the beginning of 
the investigation, the rains have been permanently, being observed peaks of very strong rainfall during the months of December to February, contrasting this situation with very little evaporation and low insolation during the same period.

\section{Results of seed germination}

\section{Analysis of variance of germination}

After the seeds had remained for a period of 10 days in the germination chamber and the germinated seeds were counted, the analysis of variance of the observed results was carried out, from the first sampling $(10 / 31 / 2000)$ to the sampling number $16(05 / 29 / 2001)$, observing statistical differences in the germination, for the depth factor of the seeds (Table 1), for which the corresponding multiple Tukey comparison test was performed.

The results of the multiple range comparison test (Table 2) shows that there are statistical differences between the different seed burial depths over time, with germination in the control being greater under $20^{\circ} \mathrm{C}$ conditions. of conservation and without burying the seeds in the soil.

Table I Results of the variance analysis of seed germination

\begin{tabular}{|c|c|c|c|c|c|}
\hline & S.c.e. & Ddl & S. means & Test f & Probab \\
\hline Var.Total & |3023.9| & 179 & 72.76 & & \\
\hline V.Time & 2150.17 & 14 & 153.58 & 7.59 & 0.0000 \\
\hline V. Depth & 5256.67 & 3 & 1752.22 & 86.57 & 0.0000 \\
\hline V.interacc & 3188.32 & 42 & 75.91 & 3.75 & 0.1000 \\
\hline V. residual & 2428.75 & 120 & 20.24 & & \\
\hline
\end{tabular}

Table 2 Results of the multiple range comparison tests, with the germination of the seeds in the different depths of burying the seeds

\begin{tabular}{|c|c|c|}
\hline Depth & Means & Groups \\
\hline Test & 24.84 & A \\
\hline $10 \mathrm{~cm}$ & 19.87 & B \\
\hline $2 \mathrm{~cm}$ & 16.44 & ( \\
\hline Superficial & 9.98 & \\
\hline
\end{tabular}

Treatments with the same letter are statistically the same

Secondly, there is the treatment that the seeds are kept buried at a depth of $10 \mathrm{~cm}$ and statistically different from the control and the others; also the treatment in which the seeds are buried at $2 \mathrm{~cm}$ depth, presents statistical treatment differences where the seeds are placed on the surface of the soil, which was the treatment that presented the least amount of germinated and viable seeds with respect to the other treatments and is statistically different from all the others.

That is, as the seeds are buried deeper, they remain viable longer, although they do not germinate in the field. Percentages of seed germination: The observation of the results of germination of the seeds through time and in the different depths of burial, it is noted that as time passes, the seeds are losing viability, a situation that is more contrast between the treatments where the seeds are on the soil surface and the seeds are buried $10 \mathrm{~cm}$ deep.

However, in spite of maintaining the tendency of the greater viability of the seeds to a greater depth of burial, the trend is not stable; this situation may be due to the strong climatic variations that have arisen. It is only important to note that in the case of seeds that are on the surface of the soil, the seeds have quickly lost their viability and the trend is very marked and it seems not reversible., Since from the fifth sampling (three months ago the test), a strong decrease in germination of seeds is observed, of approximately $10 \%$ and this tendency has been maintained until sampling 16 .

On the contrary, the treatments in which the seeds are buried at 2 and $10 \mathrm{~cm}$ depth show variations in the behaviour of the viability of the seeds, however, it is clear that the seeds that are $10 \mathrm{~cm}$ deep have higher percentages of viable seeds, than those that are $2 \mathrm{~cm}$ Deep.

It is also notorious that when the seeds are exposed to soil conditions, they suffer the effects of the various factors that coalesce in the soil, such as predators, diseases, excess humidity, lack of light, etc; since the witness in which the seeds remain at constant temperature but not in the soil, always have the highest germination rates.

\section{Results of the tetrazolium test}

Finally, when observing the results of the tetrazolium test, to define if the seeds that did not germinate are alive (documents) or are dead, ${ }^{42}$ it can be verified that in a general way, practically there are no living seeds, in all the cases in which the seeds are buried, being even more noticeable for the case of the seeds that are exposed on the surface of the soil, where the curve is very constant over time and the amount of viable seeds does not exceed $2 \%$.

However, a small peak of more viable seeds is observed in the treatments of the seeds buried at 2 and $10 \mathrm{~cm}$, between samples 6 and 8 , which may have been due to some improvement in the climatic conditions. On the contrary, the environmental control treatment, since the beginning of the trial has always presented the highest percentages of viable seeds, which shows that when the seeds are exposed to the climatic conditions of the soil, they suffer severe damages that affect the viability of the seeds. same. It is important to note that at the beginning of the trial there is a low percentage of viable seeds in the control treatment, a situation that is undoubtedly due to the fact that these seeds were stored after they were in the germination chamber, due to having problems to perform the tetrazlolium test at that time, and this situation undoubtedly caused some seeds to lose their viability

The strong expansion towards areas of grasslands, road margins and uncultivated land that Senecio inaequidens has presented, both in France, and in other European countries as mentioned, ${ }^{3}$ both in noncultivated areas and in prairie areas and vineyards, ${ }^{2}$ may be due to the fact that it is a plant that is not consumed by animals, due to its alkaloid content, ${ }^{4-10}$ which are toxic to animals, ${ }^{11,12}$ but also to their ability to disperse through the anemochoric pathways. hydrocóricas, ${ }^{2}$ as well as easy dispersal by animals, especially in the grassland areas, which occur with other Senecio species..$^{13}$ It is also important to mention that it is a plant with a large production of seeds, a situation that favors and facilitates its expansion, ${ }^{14}$ as well as other climatic-environmental factors that may favour its dispersion and expansion.

On the other hand, and in accordance with the results observed in what is taking of advances of the present project of investigation on the effects that cause him the fact of burying the seeds, in natural environmental conditions, it can be verified that when the seeds are exposed climatic conditions and remain on the surface of the soil, 
these suffer severe damage and quickly lose their viability, ${ }^{27-29}$ so it would be expected that in those areas of Meadows or uncultivated areas, where there is no soil removal, the seed bank should not be increased too much and as a consequence there should not be the strong expansion observed, as mentioned. ${ }^{13}$

However, the opposite occurs, that is, there are stronger and greater infestations in these areas, a situation that may be favoured by the fact that it is a biannual plant that can re-sprout when the climatic conditions are favourable and therefore remain in place. and added to the above, another factor that may favour its strong expansion may be the total lack of competition from other plants, especially because they have been consumed by animals, and this prevents the senecon du cap plants from dying or simply having less disposition of nutrients, water and light, besides that the own animal disperses them easily adhered to the skin, wool or in the mud that takes in the legs, since the seeds are very small. ${ }^{1}$

The above observations can be commented on because according to the results observed in this research, the seeds that are exposed on the surface of the soil quickly lose their viability, and in any case, the seeds that are buried can to conserve its viability for much longer, as has been observed in other species (viability, ${ }^{27-29}$ but in the case of meadows, especially in France, where no soil movement work is carried out, the viability of the seeds should be very low and as a consequence there should not be major problems of expansion and invasion of new prairie areas or uncultivated areas.

Also, it could be expected that as a consequence of the strong climatic variations such as temperature, insolation and rainfall, it could cause strong damage to the seeds, as they have been observed in the results obtained in the investigation and as a consequence the seed bank should not be greater problem, since the survival capacity of the seeds, when they are on the surface of the soil is very low (less than $10 \%$ ), in a very short time, less than three months.

That is to say, that surely the factors that are favouring its strong expansion, are the practices of livestock production, and that it is a plant that is not consumed by animals, with which, any plant that germinates in any prairie area, will grow and may produce the seeds that are, which can germinate without problems and grow without the competence of any other plant and gradually cover the area where they have invaded, because all the conditions are favourable. On the other hand, perhaps a good measure that could diminish the problem of invasion and expansion of this plant is, recommend the nonincorporation of plant residues, to leave the seeds exposed and favour the loss of viability and thus avoid the increase of the bank of seed and support with other control methods, trying to reduce the production of seeds, to decrease the seed bank of the soil.

\section{Conclusion}

The climatic conditions in which the research was carried out, presented a lot of precipitation and little luminosity, a situation that could have influenced the behaviour of the viability of the seeds. In general, it was observed that the seeds that are buried deeper, maintain greater viability, than the seeds that remain on the surface of the soil. It is important to note that as time passes, in any of the depths that the seeds were placed, they lose viability, but this is greater the more superficial it is. Finally, mention that the viability of the seeds, depends a lot on the environmental conditions, since the seeds that were kept as witnesses, without burying, during the whole period of the trial, they maintained the same percentages of viability

\section{Acknowledgments}

None.

\section{Conflicts of interest}

Authors declare that there is no conflict of interest.

\section{References}

1. Michez JM. Biologie et ecologie de senecio inaequidens. IXème Colloque International sur la biologie des mauvaises herbes. Dijon France. 1992;65-72.

2. Michez JM. Le seneçon du cap, de la laine à la vigne. Phytoma. 1995;468:39-41.

3. Ernst WHO. Invasion, dispersal and ecology of the south african neophyte senecio inaequidens in the Netherlands: fron wool alien to railway and road alien. Acta Bot. Neerl. 1998;47(1):131-151.

4. Barrero AF, EJ Alvarez-MR, RAM Roldan. Alcaloides pirrolizidinicos de Senecio nebrodensis L. Anales de quimica. 1991;87(3):386-390.

5. Bichi C, P Rubiolo, C Frattini. Off-line supercritical fluid extraction and capillary gas chromatography of pyrrolizidine alkaloids in Senecio species. Journal of Natural Products. 1991;54(4):941-945.

6. Vrieling K, H DeVos, AM Van Wijk. Genetic analysis of the concentrations of pyrrolizidine alkaloids in Senecio jacobaea L. Phytochemistry. 1993;32(5):1141-1144.

7. Hartmann T. XXIII Senecio spp. Biochemistry of the formulation of pyrrozilidine alkaloids in root culture. Biotechnology in Agriculture and Forestry. 1994;26:339-355.

8. Ahmed M, DA Wardle. Allelopathic potential of vegetative and flowering ragwort (Senecio jacobaea L.) plants against associated pasture species. Plant and Soil. 1994;164:61-68.

9. Brown MS, RJ Molyneux. Effects of water and mineral nutrient deficiencies on pyrrolizidine alkaloid content of Senecio vulgaris flowers. J Sci Food Agric. 1996;70:209-211.

10. Krebs HCH, T Carl, GG Habermehl. Pyrrolizidine alkaloid composition in six Brazilian Senecio species. Phytochemistry. 1996;43(6):1227-1229.

11. Mitich LW. Common groundsel (Senecio vulgaris). Weed Technology. 1995;9(1):209-211.

12. Bai Y, W Majak. Pyrrozilidine alkaloids of three species of senecio in british Columbia. Planta Med. 1996;62:71-72.

13. Wardle DA, KS Nicholson, A Rahman. Ecological effects of the invasive weed species Senecio jacobea L. (Ragwort) in New Zeland pasture. Agricultue, Ecosystems and Enviromental. 1995;56:19-28.

14. Breton S. Reproduction du Senecio inaequidens D.C. Memoire d'initiation a la recherche. Univ. De Montpellier II Sciences et Techniques du Languedoc. UFR de Biologie et Pathologie Végetale. 2000.

15. Inderjit, KI Keating. Allelopathy: Principles, procedures, processes, and promises for biological control. Advances in Agronomy. 1999;67:141-230.

16. Baskin JM, CC Baskin. Variation in the annual dormancy cycle in buried seeds of the weedy winter annual Viola arvensis. Weed Research. 1995;35:353-362.

17. Huang WZ, AI Hsiao. Factors affecting seed dormancy and germination of johsongrass, Sorghum halepense (L.) Pers. Weed Research. 1987;27:1-12.

18. Benech RLA, CM Ghersa, RA Sanchez, et al. Temperature effects on dormancy release and germination rate in Sorghum halepense (L.) Pers. Seed: a quantitative analysis. Weed Research. 1990;30:81-89. 
19. Baskin JM, CC Baskin. Germination responses of buried seeds of Capsella bursa-pastoris exposed to seasonal temperature changes. Weed Research. 1989;29:205-212.

20. Blackshaw R. Influence of soil temperature, soil moisture and seed burial depth on the emergence of round-leaved mallow (Malva pusilla). Weed Science. 1990;38:518-521.

21. Blackshaw RE. Soil temperature, soil moisture, and seed burial depth effects on redstem filaree (Erodium cicutarium) emergence. Weed Science. 1992;40:207-207.

22. Bai Y, JT Romo, JA Young. Influences of temperature, light and water stress on germination of fringed sage (Artemisia frigida). Weed Science. 1995;43:219-225.

23. Baskin CC, JM Baskin, SA El-Moursey. Seasonal changes in germination responses of buried seeds of the weedy summer annual grass Setaria glauca. Weed Research. 1996;36:319-324.

24. Grundy AC. The influence of temperature and water potential on the germination of seven different dry-stored seed lots of Stellaria media. Weed Research. 1997;37:257-266.

25. Baskin JM, CC Baskin. The role of light and alternating temperatures on germination of Polygonum aviculare seeds exhumed on various dates. Weed Research. 1990;30:397-402.

26. Martinez GMA, EH Satorre, CM Ghersa. Effect of soil water content and temperature on dormancy breaking and germination of three weeds. Weed Science. 1997;45:791-797.

27. Burnside OC, CHR Fenster, LL Evetts, et al. Germination of exhumed weed seed in Nebraska. Weed Science. 1981;29:577-586.

28. Kannangara HW, RJ Field. Enviromental and prysiological factors affecting the fate of seeds of yarrow (Achillea millefolium L.) in arable land in New Zeland. Weed Research. 1985;25:87-92.

29. Conn JS. Seed viability and dormancy of 17 weed species after burial for 4.7 years in Alaska. Weed Science. 1990;38:134-138.

30. Cussans GW, S Raudonius, P Brain, et al. Effects of depth of seed burial and soil aggregate size on seedling emergence of Alopecurus myosuroides, Galium aparine, Stellaria media and wheat. Weed Research. 1996;36:133141.
31. Ghorbani R, W Seel, C Leifert. Effects of environmental factors on germination and emergence of Amaranthus retroflexus. Weed Science. 1999;47:505-510.

32. Zorner PS, RL Zimdahl, EE Schweizer. Effect of depth and duration of seed burial on Kochia (kochia scoparia). Weed Science: 1984;32:602-607.

33. Campbell MH, HI Nicol. Effect of age on the germination of Cassia arcuata seeds in storage and buried in soil. Weed Research. 1997;37:103-109.

34. Corbineau F, D Belaid, D Côme. Dormancy of Bromus rubens L. seeds relation to temperature, light and oxygen effects. Weed Research. 1992;32:303-310.

35. Erasmus DJ, J Van Staden. Germination of chromolaena odorata (L.) K. \& R. Achenes: effect of storage, harvest locality and the pericarp. Weed Research. 1987;27:113-118.

36. Navie SC, FD Panetta, RE Mcfadyen, et al. Behaviour of buried and surface-sown seeds of parthenium hysterophorus. Weed Research. 1988;38:335-341.

37. Ren Z, RJ Abbott. Seed dormancy in mediterranean Senecio vulgaris L. New Physiol. 1991;117:673-678.

38. Donald WW. A method of validating the tetrazolium assay for testing viability of dormant jointed goatgrass (Aegilops cylindrica) seeds. Weed Science. 1994;42:502-508.

39. Bittencourt SR, RD Vieira. Use of reduced concentrations of tetrazolium solutions for the evaluation of the viability of peanut seed lots. Seed Science \& Technology. 1996;25:75-82.

40. Bittencourt SR, RD Vieira, TJD Rodriguez. Criteria for peanut seed pre-conditioning for the tetrazolium test. Seed Science \& Technology. 1997;25:337-342.

41. Deswal DP, U Chand. Standarization of the tetrazolium test for viability estimation in ricebean (Vigna umbellata) (Thumb.) Ohwi \& ohashi) seeds. Seed Science \& Technology. 1997;25:409-417.

42. Kuo WHJ, AC Yan, N Leist. Tetrazolium test for the seeds of Salvia splendens and Salvia farinacea. Seed Science Technology. 1996;24:17-21. 